\title{
Hydrothermal Aging and Bonding Properties of a New Room Temperature Cured Structural Adhesive in Building Components
}

\author{
Hui $\mathrm{Li}^{1}$, Guan Gong ${ }^{1 *}$, Tian $\mathrm{Lv}^{2}$ \\ ${ }^{1}$ College of Architecture and Civil Engineering, Xinyang Normal University, Xinyang, China \\ ${ }^{2}$ China Petrochemical Corporation, Beijing, China
}

Corresponding Author Email: lihui025@xynu.edu.cn

https://doi.org/10.18280/acsm.450410

Received: 11 March 2021

Accepted: 8 June 2021

\section{Keywords:}

structural adhesives, hydrothermal aging, dynamic mechanical analysis, concrete repair,

bonding rebars to concrete

\begin{abstract}
This paper firstly explores the hydrothermal aging performance of a new room temperature cured structural adhesive at four different levels of relative humidity through dynamic mechanical analysis (DMA). The results show that the strengthening effect of post-curing was stronger than weakening effect of humidity. Then, the Arrhenius equation was introduced to calculate the ratio of the apparent activation energy of this adhesive at the glass transition temperature before and after hydrothermal aging. The little change of the ratio suggests that the adhesive boasts a strong resistance to hydrothermal aging. In addition, the adhesive was tested on concrete structures at room temperature to observe its repairing effect of concrete cracks. The observations reveal that the compressive strength of the cracked concrete block repaired by the adhesive was as high as $90.5 \%$ of that of the intact concrete block. Furthermore, the adhesive was used to bond rebars to concrete under three different constant tensile speeds. The results demonstrate that the bonding effect was better under slow constant loading.
\end{abstract}

\section{INTRODUCTION}

Engineering structures with decades or even centuries of service life undergo significant changes in the environment. Through the long-term service, the structural adhesive, a common bonding polymer in building structures, ages physically. This material has many attractive properties, namely, high strength and stiffness, excellent adhesive property, strong corrosion resistance, as well as good insulation and thermal performance. However, the physical aging of the adhesive involves both macro- and microvariations of molecular construction and constitution, causing property changes and even material failure. This will threaten the safety and stability of engineering structures. Besides, the long-term performance of adhesive during the service period is also greatly affected by the presence of post-curing [1-3]. Therefore, recent studies on the aging of epoxy materials have paid much attention to the exposure to environmental factors like humidity, thermal, light, and post-curing [4-7]. It is important to grasp the law and influence of physical aging of structural adhesive in various complex environments $[8,9]$.

In the past decades, there were many theoretical and experimental analyses on how temperature or humidity affect the property of epoxy adhesive. The results demonstrate that a short time is recommended for thermal aging experiments on the adhesive, because temperature significantly affects the adhesive property in a short period [10-15]. In general, fewer scholars examined the effect of humidity on epoxy resin adhesive, a typical amorphous cross-linked polymer, than that of temperature. As the bonding interface is damaged by moisture, the interface strength of epoxy resin adhesive will degrade obviously in the long term under the hydrothermal environment. Besides, the interface damage induced by moisture will be accelerated by temperature [16-18], causing degradation of adhesive properties and even failure of the bonding interface. Therefore, hydrothermal aging has a nonnegligible impact on adhesive performance.

For the above reasons, quite many scholars have put the epoxy resin adhesive in water at constant temperature, trying to manually speed up the aging process, and disclose the effect of humidity on the adhesive [19-25]. This approach can indeed reduce the time cost of the experiment. However, immersion in water with constant temperature is not an exact reproduction of the actual service environment of epoxy resin adhesive. A few researchers replaced this approach with a hydrothermal aging oven, with the aim to simulate the service environment of the epoxy resin adhesive.

In polymer research [26-29], the time-dependent properties of materials under dynamic load are often investigated with the characterization technique of dynamic mechanical analysis (DMA). Nonetheless, this technique has rarely been applied to characterize the aging procedure of epoxy resin adhesive, compared with the common metrics like the change of tensile strength and moisture absorption rate. In fact, it is more in line with the actual situation to characterize the performance of adhesives before and after aging in building structures with dynamic mechanical properties. After that, the dynamic load is more common than static load in building structure, such as crowd load on the floor, vehicle load on bridge, etc.

A lot of efforts have been made to modify epoxy resin [18, 30, 31]. For example, the strength and stiffness can be improved to a certain extent by adding fibers. To realize the expected performance, the adhesive must be cured under proper conditions (e.g., temperature and time) [32]. In most cases, the developed adhesives are applied outdoor in civil engineering, even in remote areas without any external heat 
source. Hence, the adhesive used to strengthen engineering structures should be easy to operate, and able to cure in simple conditions. Some cold curing structural epoxy adhesives could cure at a low temperature and perform well, but their glass transition temperature is as low as $70^{\circ} \mathrm{C}$ [33-35].

Many have reported the significant effects of curing temperature on durability indices [36-38]. Normally, the curing temperature is positively correlated with the performance of epoxy adhesive. Yet, some modified structural epoxy adhesives weaken with the substantial growth of modifiers like tougheners and diluents [39]. Considering the economy and practicability, the newly developed structural epoxy resin adhesive should be able to cure at room temperature, and reach a sufficient strength in the natural environment, without modification or any additional condition. In this paper, the target epoxy resin adhesive is a structural adhesive for reinforcing, repairing, and bonding in building structures, such as to combine different construction materials into an integral load-bearing system.

To comprehensively describe the properties of the adhesive, the bonding effect between the structural adhesive and the building materials should be characterized, in addition to the behavior of adhesive. For this reason, it is important to evaluate the performance of the adhesive in the actual structure. However, most scholars have emphasized the performance of adhesive itself, e.g., tensile strength, shear strength, and peel strength [34, 37-38] over the performance of the integral system composed of the structural adhesive and building materials. This is attributable to two facts: One the one hand, the testing instruments are too limited to test the whole building structure or components, owing to their large volume and weight. On the other hand, it is difficult to guarantee the quality of the concrete components needing a long period of maintenance and production.

The target structural adhesive has already been discussed in the previous work, which explores the change of performance in a single and constant humidity environment and the tensile creep behavior [40, 41]. In this paper, the room temperature cured structural adhesive was tested under four levels of relative humidity, using a hydrothermal aging oven, and then applied to actual concrete components. The hydrothermal resistance of the adhesive was measured by the aging performance index of dynamic mechanical properties. Moreover, the application effect of the adhesive in the structural components was evaluated comprehensively through tests. The research findings not only provide a desired DMA method to probe the performance of the new epoxy adhesive under potential complex environments, but also shed new lights on the application of the adhesive in engineering structures.

\section{MATERIALS AND SAMPLE PREPARATION}

The new structural adhesive needs to be prepared from the following materials: E51 and F51 commercial epoxy resins (Wuxi Xingchen Chemicals Co., Ltd., China); Qishi QS-BE toughening agent (Beijing Jingdao Qishi Materials Sci. \& Tech. Co., Ltd., China); m-Xylylenediamine (m-XDA) hardener (Xiamen Grandachem Co., Ltd., China).

The new structural epoxy resin adhesive should live up to the performance standard in ASTM D2990 [43]. Therefore, the samples were cured at room temperature for 7 days. Then, the tensile strength and the elongation at break of the adhesive were measured as $55 \mathrm{MPa}$ and $3.77 \%$ with a universal electronic testing machine (MTS Industrial Co., Ltd., China). The results are superior to the requirements on type A structural adhesives (tensile strength $>30 \mathrm{MPa}$; elongation at break $>1.2 \%$ ) for concrete reinforcement in the Technical Code for Safety Appraisal of Engineering Structural Strengthening Materials (GB50728-2011) [42].

The adhesive sample for tensile test, and that for hydrothermal aging test are given in Figures 1 and 2, respectively. The latter sample is of the size $25 \mathrm{~mm}$ (length), $5 \mathrm{~mm}$ (width), and $2.5 \mathrm{~mm}$ (thickness).

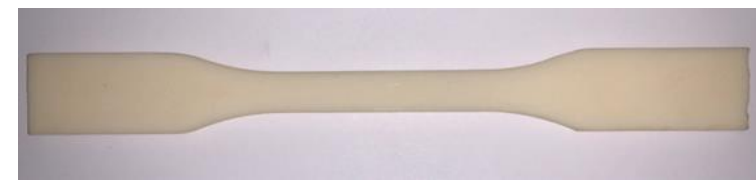

Figure 1. Tensile test sample

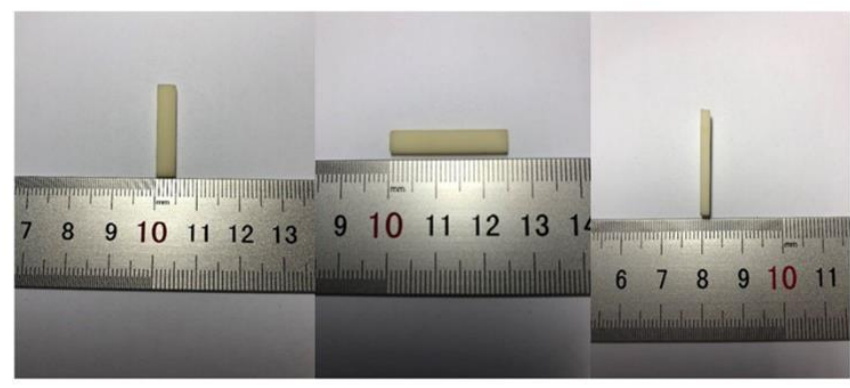

Figure 2. Hydrothermal aging test sample

\section{HYDROTHERMAL AGING TEST}

\subsection{Instruments and test plan}

Each test sample (Figure 2) was cured at room temperature, and then put into the hydrothermal aging oven (Huaxia Technology Co., Ltd., China). The sample was subjected to hydrothermal aging tests under the constant temperature of $70^{\circ} \mathrm{C}$ and four relative humidity levels $(65 \%, 75 \%, 85 \%, 95 \%)$ for 30 days. Then, the changing properties of the adhesive were characterized by the DMA 8000 rheometer.

In each test, temperature and frequency scans were performed, using the single cantilever bending mode, on both aged and unaged samples. The mean results were taken as the outcome. During the temperature scan, the temperature was elevated from room temperature to $150^{\circ} \mathrm{C}$ at the rate of $2{ }^{\circ} \mathrm{C} / \mathrm{min}$, with the strain of $0.1 \%$. In the frequency scan, the frequency was changed from $0.01 \mathrm{~Hz}$ to $100 \mathrm{~Hz}$ under seven test temperature levels $\left(40^{\circ} \mathrm{C}, 50^{\circ} \mathrm{C}, 60^{\circ} \mathrm{C}, 70^{\circ} \mathrm{C}, 80^{\circ} \mathrm{C}, 90^{\circ} \mathrm{C}\right.$, $100^{\circ} \mathrm{C}$ ), with the strain of $0.1 \%$ at each temperature.

\subsection{Results and discussion}

\subsubsection{Temperature spectrum}

As shown in Figure 3(a), the storage modulus $\left(E^{\prime}\right)$ of the epoxy resin adhesive was $1.7 \mathrm{GPa}$, corresponding to the curve of aged sample at room temperature. $E^{\prime}$ is defined as the ratio of stress to strain when the strain lags a certain phase angle of stress.

After aging at different humidity levels for 30 days, the $E^{\prime}$ of aged samples were all higher than that of the unaged sample. 
The reason for this phenomenon is as follows: The adhesive simultaneously faces the post-curing enhancement by high temperature and intermolecular weakening by high humidity; the former effect is stronger than the latter effect.
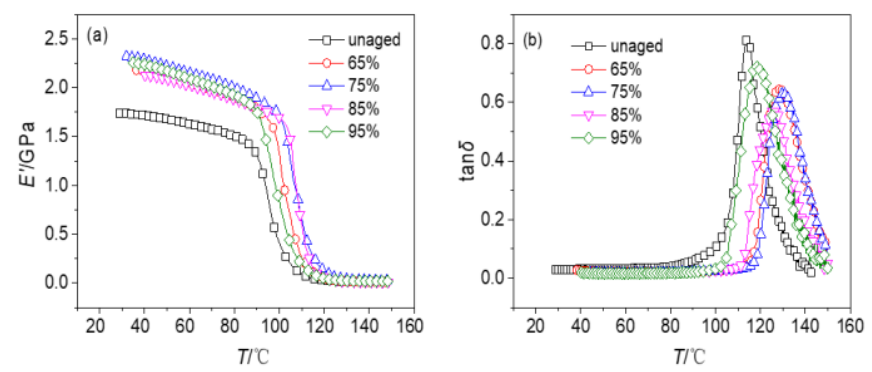

Figure 3. (a) $E^{\prime}-T$ curves and (b) $\tan \delta$ - $T$ curves of samples under the constant temperature of $70^{\circ} \mathrm{C}$ and four levels of relative humidity after 30 days

As the test temperature increased from room temperature to $90^{\circ} \mathrm{C}$, the $E^{\prime}$ at the relative humidity of $65 \%$ and $75 \%$ were improved in turn, while that at the relative humidity of $85 \%$ and $95 \%$ were low than that at the relative humidity of $65 \%$ and $75 \%$ (Figure 3(a)). Further temperature growth significantly suppressed the $E^{\prime}$ at the relative humidity of $95 \%$.

The sharp decrease of $E^{\prime}$ at the relative humidity of $95 \%$ is attributable to the strong impact of swelling and plasticization on the adhesive at that ambient humidity. From the perspective of molecular structure, polymers can resist the damage of external forces, thanks to the chemical bond force within molecules, as well as the van der Waals force and hydrogen bond between molecules. Water absorption will cause the material to swell and plasticize, and damage the of van der Waals force and hydrogen bond between macromolecular chains. Then, the material will enter the glass transition zone at a lower temperature. The resulting strain increment will lead to a smaller stress and $E^{\prime}$.

The $\tan \delta$ - $T$ curve is sensitive to the property change of polymer molecules. Thus, glass transition temperature $(T g)$ can be determined accurately by the peak of $\tan \delta$ - $T$ curve. Corresponding to the peak value of the unaged sample in Figure 3(b), the $\operatorname{Tg}\left(108^{\circ} \mathrm{C}\right)$ of the structural adhesive was far higher than the level $\left(70^{\circ} \mathrm{C}\right)$ reported by some scholars $[35,36]$ for the room temperature-cured adhesive. Table 1 lists the $T g$ of this adhesive under different ambient conditions.

Table 1. $T g$ of samples under different aging conditions

\begin{tabular}{cccccc}
\hline & Unaged & Relative humidity of $65 \%$ & Relative humidity of $75 \%$ & Relative humidity of $85 \%$ & Relative humidity of $95 \%$ \\
\hline$T g$ & $108^{\circ} \mathrm{C}$ & $121^{\circ} \mathrm{C}$ & $122^{\circ} \mathrm{C}$ & $120^{\circ} \mathrm{C}$ & $119^{\circ} \mathrm{C}$ \\
\hline
\end{tabular}

Some hydrothermal aging tests $[43,44]$ indicate that, the right shift of the peak of the $\tan \delta$ - $T$ curve equals the improvement of $\mathrm{Tg}$ and enhancement of crosslink density. That is, the $\tan \delta$ - $T$ curve characterizes the changing performance of the material.

As shown in Figure 3 (b), the four samples aged at four different levels of relative humidity all had a higher $\mathrm{Tg}$, i.e., the temperature corresponding to the peak of the $\tan \delta$ - $T$ curve, than the unaged sample. This is attributable to the crosslink density improved by post-curing, which occurs along with hydrothermal aging.

With the increase of humidity, the $T g$ of the adhesive increased successively from unaged to the aged at relative humidity of $65 \%$ and $75 \%$. As the relative humidity reached $85 \%$ and $95 \%$, the peak of the $\tan \delta$-T curve moved leftward in the direction of low temperature, compared with that at the relative humidity of $65 \%$ and $75 \%$. This phenomenon is consistent with the above analysis, revealing that the long-term exposure to high humidity breaks the molecular chains, making them more flexible.

From unaged to the relative humidity of $65 \%$ and $75 \%$, the peak of the $\tan \delta$-T curve gradually declined. Meanwhile, the peak width narrowed significantly in the late phase of aging, for the absorbed water lubricates the molecular chains and reduces the loss. As a result, the $E^{\prime}$ at the relative humidity of $65 \%$ and $75 \%$ was better than at of the unaged.

\subsubsection{Frequency spectrum}

As shown in Figure 4, for the unaged sample and the samples aged at four levels of relative humidity $(65 \%, 75 \%$, $85 \%, 95 \%$ ) for 30 days, the $E^{\prime}-f$ curves varied roughly the same at different test temperatures $\left(40^{\circ} \mathrm{C}, 50^{\circ} \mathrm{C}, 60^{\circ} \mathrm{C}, 70^{\circ} \mathrm{C}, 80^{\circ} \mathrm{C}\right.$, $90^{\circ} \mathrm{C}, 100^{\circ} \mathrm{C}$ ).

Under a fixed test frequency, the storage modulus $E^{\prime}$ declined successively with the increase of test temperature. Since the frequency, i.e., the observation time $t$, is fixed at a value smaller than the relaxation time $\tau$ of molecular movement unit, the movement of the unit is not observable within the limited observation time $t(\tau \geq t)$. In the meantime, the chain segment movement is frozen, and the epoxy resin adhesive is in the glass state, with a large storage modulus.
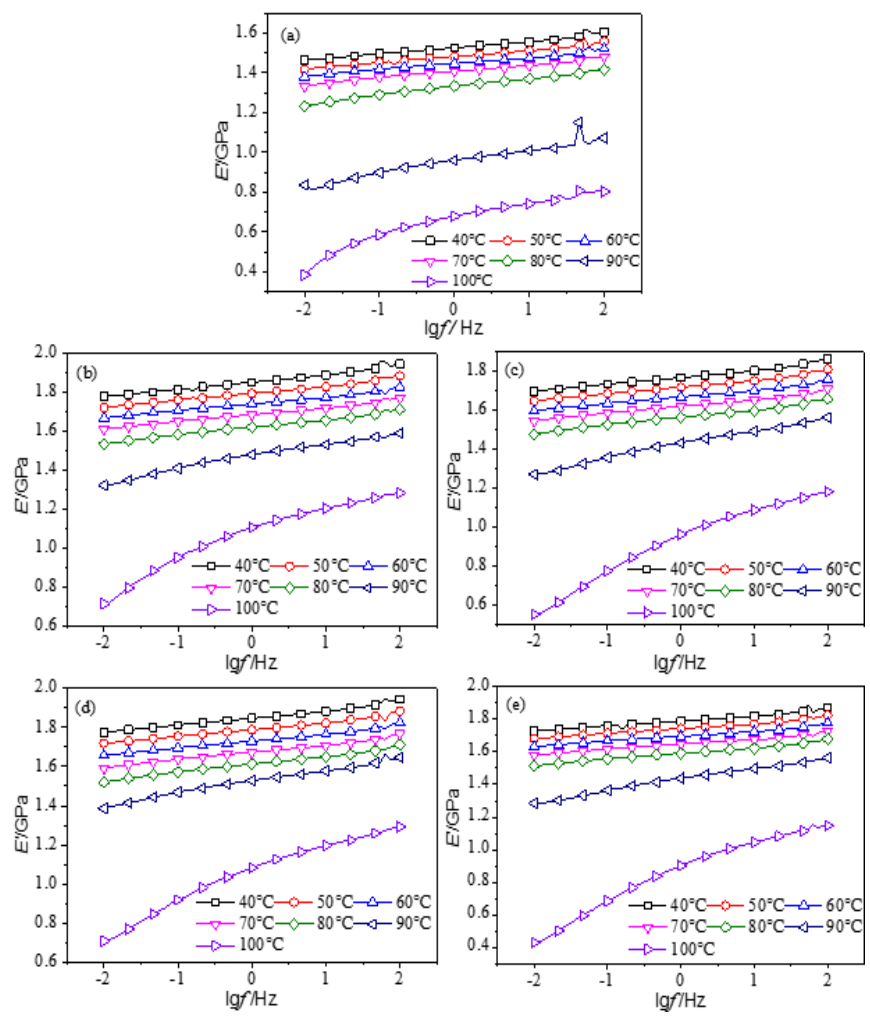

Figure 4. $E^{\prime}-f$ curves at different levels relative humidity under different test temperatures (a)unaged, (b) $65 \%$, (c)75\%, (d) $85 \%$, (e) $95 \%$ 
As $\tau$ decreases with the increase of the test temperature, the movement can be fully observed within the observation time when $\tau \leq t$. In this case, the free chain segment movement brings a highly elasticity to the epoxy resin adhesive at the small storage modulus $E^{\prime}$. Nevertheless, the positive correlation between $E^{\prime}$ and test frequency $f$ comes from the fact that: a high test frequency increases the lag of the movement of the internal molecular chain segment behind the change of the external force; with the decrease of internal friction, the material becomes more stiff, resulting in the rise of $E^{\prime}$.

As the test temperature rose from $40^{\circ} \mathrm{C}$ to $80^{\circ} \mathrm{C}$, the variation of $E^{\prime}$ was small, and the $E^{\prime}-f$ urves were relatively gentle. Once the temperature climbed up to $90^{\circ} \mathrm{C}$, the $E$ increased dramatically, and the $E^{\prime}-f$ curves became steep. Moreover, the slope of the curves $E^{\prime}-f$ increased with the humidity at $90^{\circ} \mathrm{C}$ and $100^{\circ} \mathrm{C}$ (Figures $4($ a) $-4(\mathrm{e})$ ).
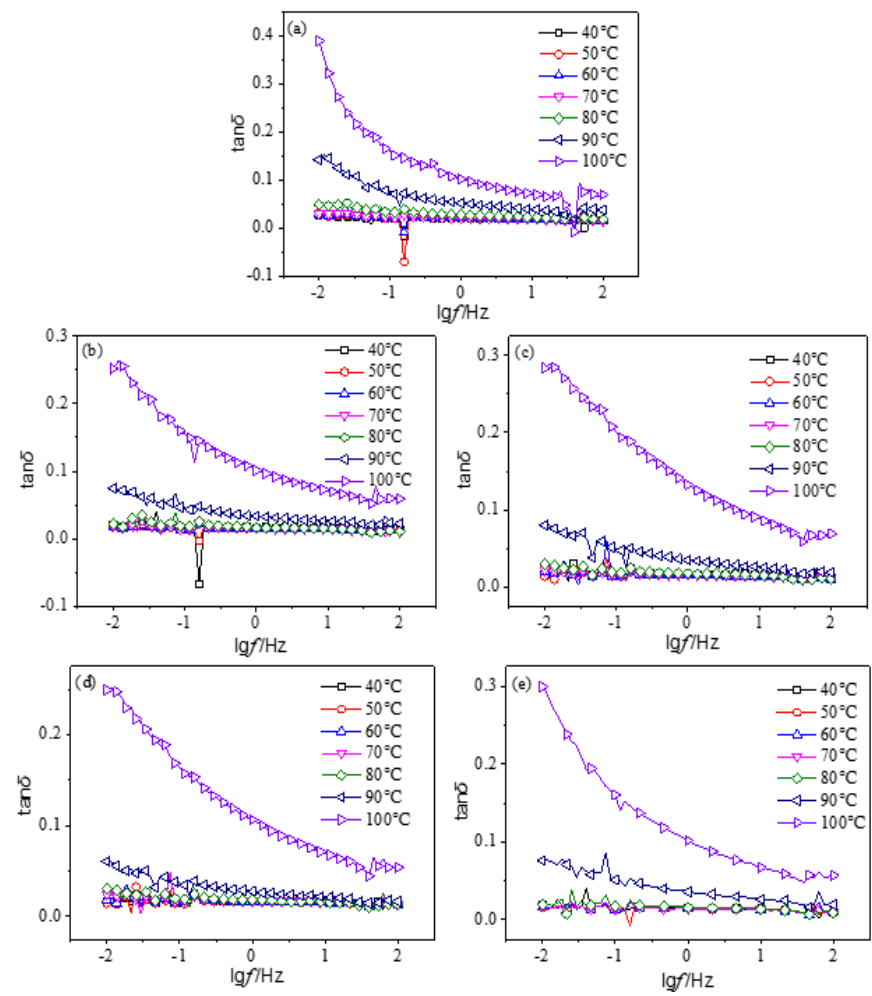

Figure 5. $\tan \delta-f$ curves at different levels relative humidity under different test temperatures (a)unaged, (b)65\%, (c)75\%, (d) $85 \%$, , e) $95 \%$

The trend of $\tan \delta-f$ curves at different levels relative humidity (Figure 5) was consistent with the analysis results of Figure 4. Since the chain segment movement is frozen under low test temperatures $\left(40^{\circ} \mathrm{C}, 50^{\circ} \mathrm{C}, 60^{\circ} \mathrm{C}, 70^{\circ} \mathrm{C}, 80^{\circ} \mathrm{C}\right)$, it is necessary to overcome the friction among the chain segments. That is why the internal friction was small, and the $\tan \delta$ - $f$ curves remained basically unchanged. As the temperature rose to $90^{\circ} \mathrm{C}, 100^{\circ} \mathrm{C}$, the chain segments shift from the frozen state to free state, and their movement needs to overcome a large friction force. Hence, the internal friction increased, i.e., $\tan \delta$ increased.

\section{THERMODYNAMIC ANALYSIS}

To further reveal the effects of hydrothermal aging on the properties of epoxy curing system, the apparent activation energy of glass transition, a metric of the degree of hydrothermal aging, before and after hydrothermal aging were calculated by Arrhenius equation $[45,46]$. The dependence of molecular motion on temperature and frequency obeys Arrhenius equation:

$$
\tau=\tau_{0} e^{\Delta E / R T}
$$

where, $\tau_{0}$ is a constant; $R$ is a gas constant; $T$ is absolute temperature; $f$ is a frequency with unit $\mathrm{Hz} ; \Delta E$ is the activation energy required for unit motion. Substituting $\tau=\frac{1}{2 \pi f}$ for $\tau$, the logs of the two sides of formula (1) can be obtained:

$$
\begin{gathered}
\ln (2 \pi f)=-\ln \tau_{0}-\Delta E / R T \\
\text { or } \ln f=A-\Delta E / R T
\end{gathered}
$$

When the glass transition temperature $T g$ equals $T, \Delta E$ is the activation energy of chain segment motion.

In the DMA test, the test frequency was set to $1 \mathrm{~Hz}$ under different hydrothermal aging conditions. Hence, formula (3) can be converted into:

$$
\Delta E_{1} / \Delta E_{2}=T g_{1} / T g_{2}
$$

Hence, the ratio of activation energy equals the ratio of glass transition temperature (absolute temperature). The activation energy of the chain segment of the unaged $\left(\Delta E_{\text {unaged }}\right)$ was set as 1 , and the ratio of the activation energy under another hydrothermal aging condition to $\Delta E_{\text {unaged }}$ are listed in Table 2.

Table 2 shows that the chain segment activation energy of epoxy resin adhesive changed little, indicating that the adhesive performance remains stable as the relative humidity increases from $65 \%$ to $95 \%$. Therefore, the adhesive boasts a strong resistance to hydrothermal aging.

Table 2. The ratio of activation energy under different aging conditions condition to $\Delta E_{\text {unaged }}$

\begin{tabular}{lccccc}
\hline & Unaged & $\begin{array}{c}\text { Relative humidity } \\
\text { of } 65 \%\end{array}$ & $\begin{array}{c}\text { Relative humidity } \\
\text { of } 75 \%\end{array}$ & $\begin{array}{c}\text { Relative humidity } \\
\text { of } 85 \%\end{array}$ & $\begin{array}{c}\text { Relative humidity } \\
\text { of } 95 \%\end{array}$ \\
\hline Glass transition temperature $\mathrm{Tg}$ & 1 & 1.03412 & 1.03674 & 1.03149 & 1.02887 \\
\hline
\end{tabular}

\section{APPLICATION EXPERIMENTS}

\subsection{Repair and reinforcement of cracked concrete}

\subsubsection{Sample preparation}

To evaluate the repair and reinforcement effect of the adhesive on cracked concrete, 18 rectangular concrete test blocks (length: $150 \mathrm{~mm}$; width: $150 \mathrm{~mm}$; height: $300 \mathrm{~mm}$ ) were prepared. Six of the blocks are without prefabricated cracks (hereinafter referred to as intact blocks), and the other twelve are with prefabricated cracks. The blocks were manufactured from ordinary Portland cement PO 32.5, 
medium sand $(4.85 \mathrm{~mm})$ as fine aggregate, and crushed gravel $(32.5 \mathrm{~mm})$ as coarse aggregate. The mix ratio was as follows: water: cement: coarse aggregate: fine aggregate: sand $=19: 50$ : 120: 55: 59. No additive was added. The cracked blocks each had two symmetrical cracks $(150 \mathrm{~mm} \times 30 \mathrm{~mm} \times 2 \mathrm{~mm})$ on the two symmetrical planes in the middle of its height (Figure $6)$.

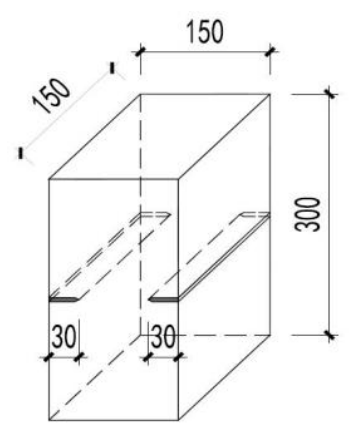

Figure 6. Dimension of cracked sample (mm)

The cracked blocks were manufactured in the following steps: To save time, concrete was poured into the symmetric wooden mold simultaneously to make concrete blocks. First, two rabbets were opened at the top and bottom of each mold, respectively. A thin steel sheet was then inserted through each rabbit to create the cracks. Figure 7 shows the mold of cracked sample. By the above-mentioned mix ratio, the mixture was stirred evenly, put into the mold, compacted, and smoothed over the top (Figure 8). After initial setting, the steel sheets were removed to form the prefabricated cracks. After another 24 hours, the mold was taken away, and each block was maintained under the standard condition for 28 days. In this way, a cracked block was obtained (Figure 9). Next, each cracked block was repaired and strengthened with the structural adhesive, and cured at room temperature for 7 days (Figure 10). Both intact and cracked blocks were maintained for the same period, $35(28+7)$ days, under standard conditions, before subsequent tests.

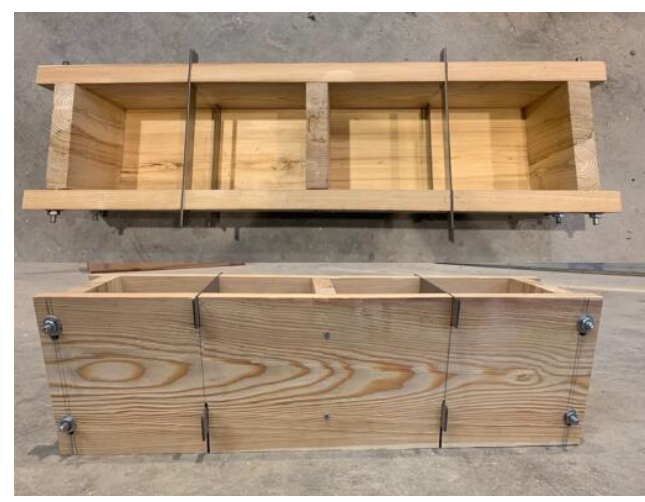

Figure 7. Mold of cracked concrete block

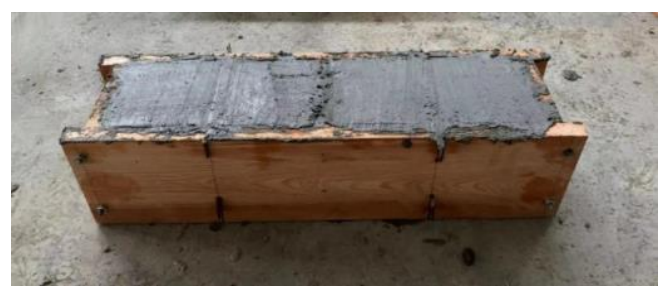

Figure 8. Preparation process of cracked concrete block

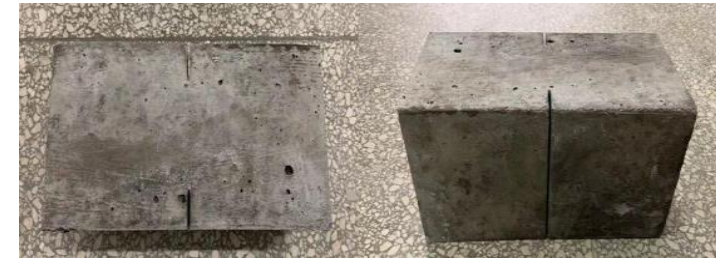

Figure 9. Cracked concrete block

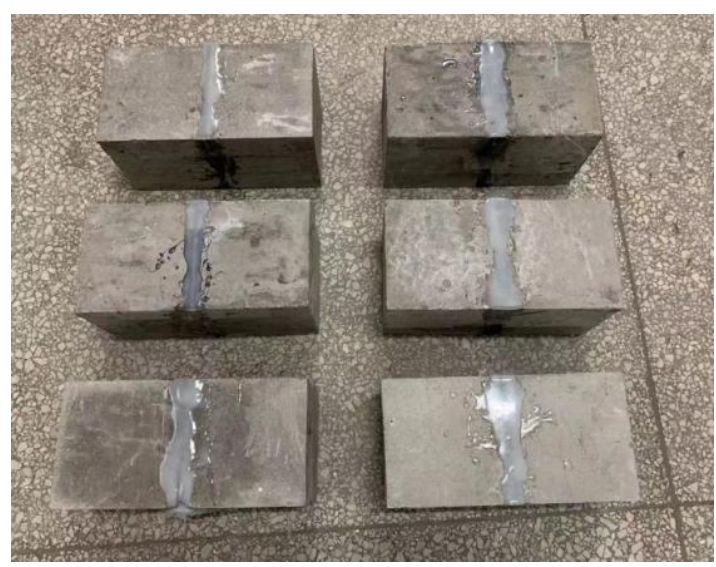

Figure 10. Repaired concrete block

\subsubsection{Compressive tests and discussion}

The mean compressive strength of 18 test blocks were obtained through compressive tests, and used to evaluate the repair and strengthening effect of the adhesive on cracked concrete. During the tests, the 6 intact blocks, 6 cracked and unrepaired blocks, and 6 cracked blocks repaired by the adhesive were labeled $\mathrm{C} 1, \mathrm{C} 2$, and $\mathrm{C} 3$, respectively. The test equipment was a TYE-2000E test machine. The test procedure is shown in Figure 11. The test results are recorded in Table 3.

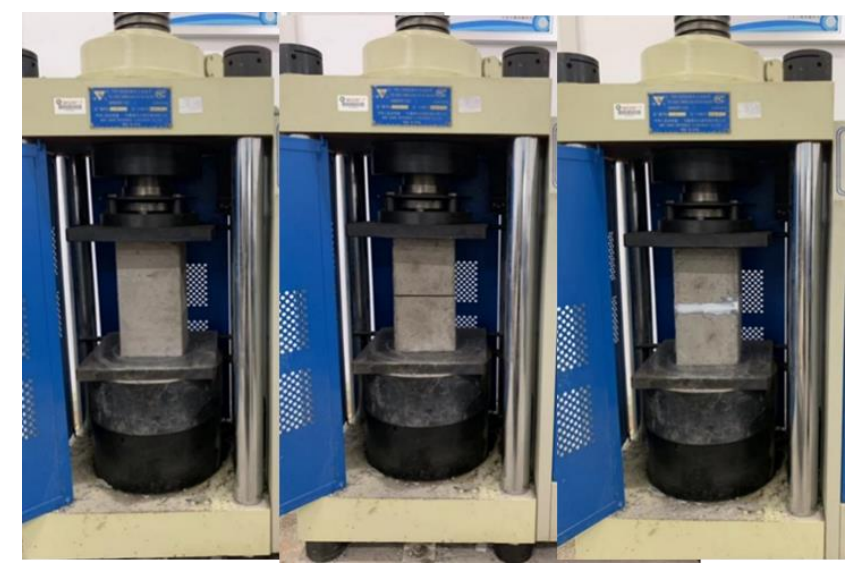

Figure 11. Procedure of compressive tests

Table 3. Compressive strengths of three types of samples (MPa)

\begin{tabular}{cccccccc}
\hline & 1 & 2 & 3 & 4 & 5 & 6 & Mean \\
\hline C1 & 32.9 & 28.5 & 33.4 & 32.5 & 31 & 30.5 & 31.5 \\
C2 & 18.8 & 20.3 & 22.3 & 21.3 & 14.3 & 19.4 & 19.4 \\
C3 & 30 & 25.9 & 29 & 28.6 & 28.6 & 28.6 & 28.5 \\
\hline
\end{tabular}

The mean compressive strengths of $\mathrm{C} 1, \mathrm{C} 2$, and $\mathrm{C} 3$ were $31.5 \mathrm{MPa}, 19.4 \mathrm{MPa}$, and $28.5 \mathrm{MPa}$, respectively. For convenience, these results were plotted into a histogram (Figure 12). The compressive strength of $\mathrm{C} 2$ was $61.6 \%$ of that 
of $\mathrm{C} 1$, and that compressive strength of $\mathrm{C} 3$ was $90.5 \%$ of that of $\mathrm{C} 1$. The comparison demonstrates that the adhesive has a great effect on repairing cracked concrete: the bearing capacity of cracked sample can be restored to more than $90 \%$ of the original level of intact sample.

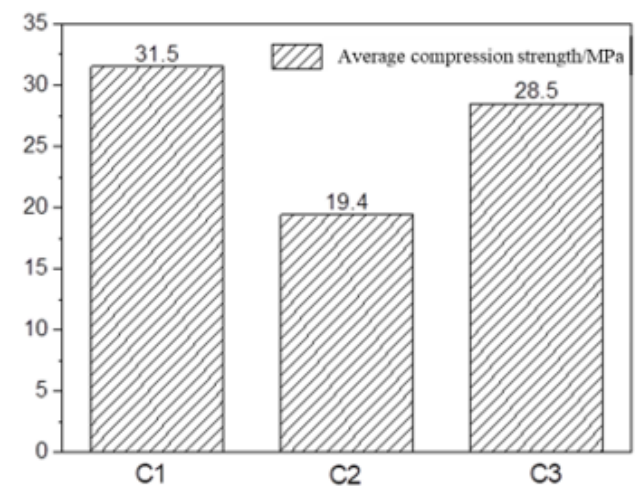

Figure 12. Histogram of mean compressive strength of $\mathrm{C} 1$, $\mathrm{C} 2$, and $\mathrm{C} 3(\mathrm{MPa})$

\subsection{Bonding tests on reinforced concrete}

Apart from bearing compressive load, concrete in building structures is expected to reinforce the structures by combining with rebars. The reliable bonding between rebars and concrete underpins the safety of the whole building. In practical engineering, most reinforced concrete structures are casted simultaneously. Meanwhile, expansion and reinforcement projects need to add new rebars or new concrete to the preexisting concrete structures. In these projects, adhesives and other bonding materials should be applied to connect rebars and concrete, turning them into an entirely for load bearing. Therefore, this subsection tries to probe into the bonding effect of the adhesive on the rebars and concrete through bonding tests.

\subsubsection{Sample preparation}

Figure 13 shows the dimension of the reinforced concrete sample for bonding tests: $250 \mathrm{~mm} \times 150 \mathrm{~mm} \times 150 \mathrm{~mm}$ (length $\times$ width $\times$ height). The size is identical to that in the previous subsections. The sample uses No. 16 deformed rebar with the length of $400 \mathrm{~mm}$. The bonding length was set to $180 \mathrm{~mm}>10$ $\mathrm{d}$ ( $\mathrm{d}$ is rebar diameter) between the rebar and the concrete.

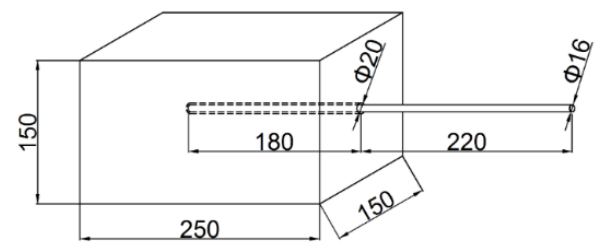

Figure 13. Dimension of reinforced concrete (mm)

Figure 14 presents the mold for the samples of the bonding tests. The mold consists of a box and two brackets. To save time, concrete was poured into the symmetric box made of bolt-connected planks simultaneously. Two holes (diameter: $20 \mathrm{~mm}$ ) were reserved at the center of the side of the box for penetrating rebar. The outer end of the rebar should be placed on the bracket to avoid deviating from the center.

For comparison, a total of twelve samples were fabricated, of which six were manufactured simultaneously in the following process: Firstly, a rebar was inserted via a hole of the mold, with the other end on the brackets; Next, the prepared concrete was poured into the box, and vibrated with a vibrator. Finally, the mold was removed after 24 hours, and the specimens were maintained for 28 days under the standard condition. Figure 15 shows the reinforced concrete sample.

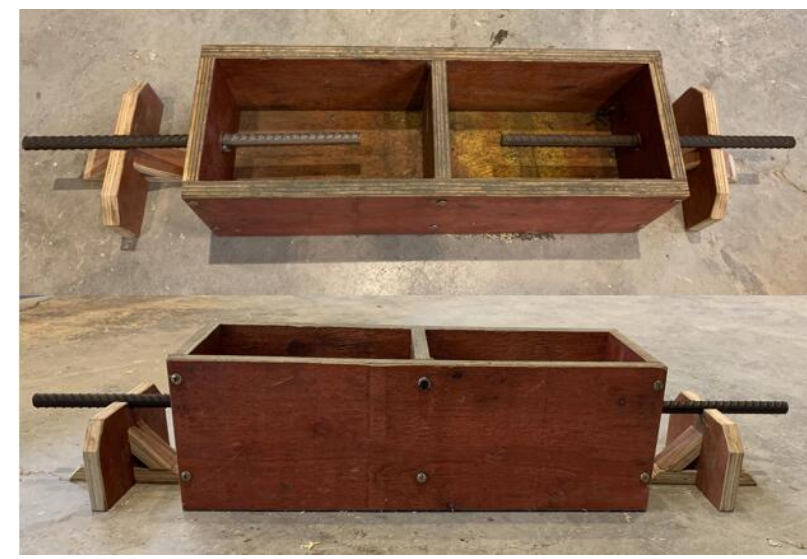

Figure 14. Mold for samples of the bonding tests

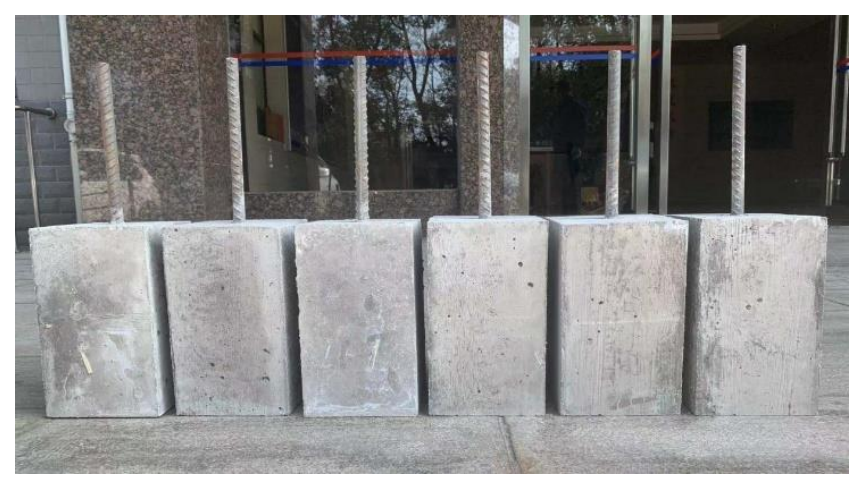

Figure 15. Reinforced concrete sample

The other six samples were fabricated by applying the adhesive to bond rebars and concrete. The manufacturing process was as follows: Firstly, one end of gauze-wrapped hollow steel pipe (diameter: $20 \mathrm{~mm}$ ) was passed through a reserved hole to roughen its inner surface, and increase the bonding areas between adhesive and concrete, with the other end on the brackets. Next, the prepared concrete was poured into the box, and vibrated with a vibrator (Figure 16). After initial setting, the hollow steel pipe was pulled out; the mold was removed after 24 hours. The samples (Figure 17) were maintained under standard conditions for 28 days. Finally, the adhesive was injected into the reserved hole, and No.16 rebar was inserted into the bottom of the hole while rotating. To prevent the formation of a concave liquid surface at the hole, the adhesive should exceed the hole by about $2 \mathrm{~mm}$, and cured at room temperature for 7 days before subsequent tests (Figure 18).

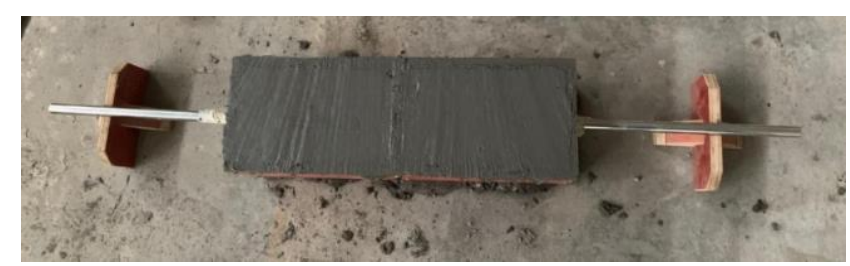

Figure 16. Manufacturing process of sample with holes 


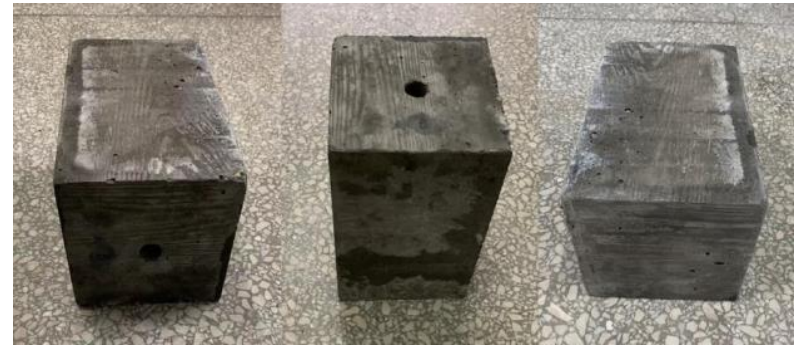

Figure 17. Concrete sample with holes

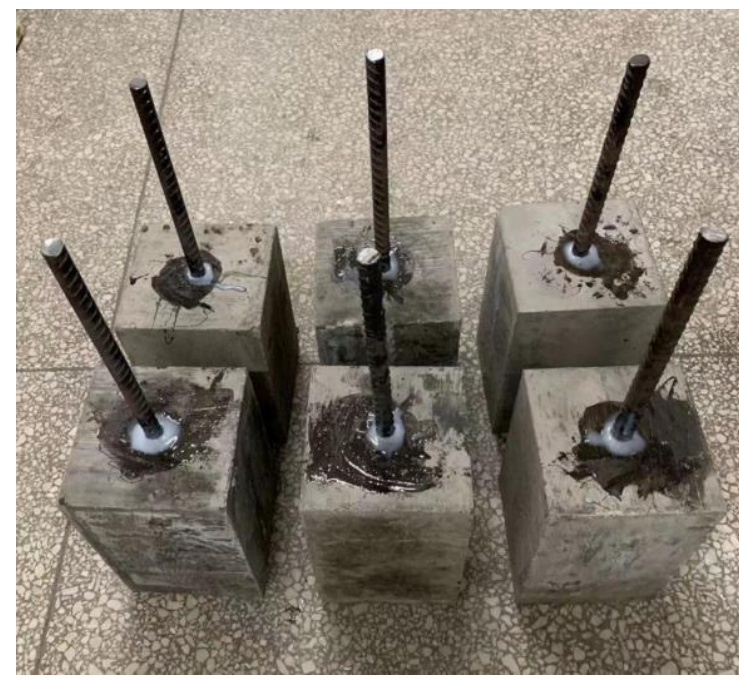

Figure 18. Reinforced sample bonded with adhesive

\subsubsection{Test and discussion}

Each reinforced concrete sample is symmetry with only one end of rebar. Therefore, it is impossible to adopt the universal testing machine in the bonding tests. For this, a drawing auxiliary device, which includes steel plate, anchor bolt, bolt, and rebar, was designed (Figure 19). The designed device was patented in China (No.: ZL 20142 0243024.5). Then, each sample was loaded into the device, turning into a symmetrical sample. To prevent the device from being damaged, the steel plate was welded with the bolt, and No. 20 deformed rebar (diameter: $20 \mathrm{~mm}$ ) thicker than the rebar in the sample was selected.

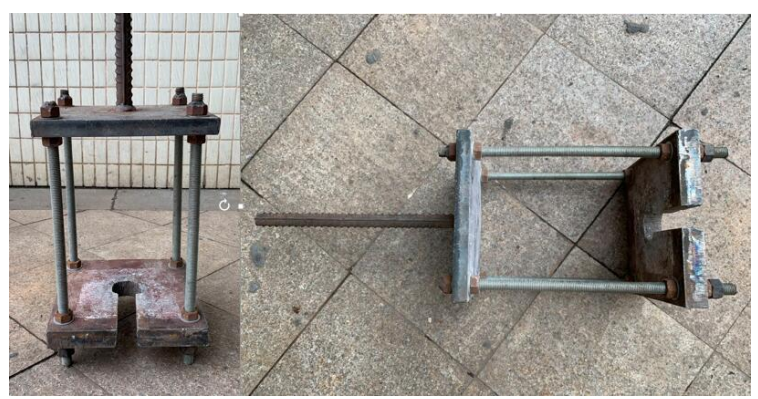

Figure 19. Auxiliary device

The samples without adhesive and with adhesive were labelled as WJ and $\mathrm{J}$, respectively. Considering the great impact of loading speed on the bond force between rebar and concrete, three different constant loading speeds $(0.2 \mathrm{kN} / \mathrm{s}$, $0.5 \mathrm{kN} / \mathrm{s}, 0.8 \mathrm{kN} / \mathrm{s}$ ) were selected for the bonding tests. The two kinds of samples were divided into three groups. In each group, two samples were arranged for each constant loading speed.
Figure 20 shows the test device and procedure. Table 4 displays the test results.

Table 4. Maximum destructive force of $\mathrm{WJ}$ and $\mathrm{J}$ at different constant loading speeds

\begin{tabular}{cccc}
\hline & $0.2 \mathrm{kN} / \mathrm{s}$ & $0.5 \mathrm{kN} / \mathrm{s}$ & $0.8 \mathrm{kN} / \mathrm{s}$ \\
\hline J-1 & 81.96 & 73.67 & 69 \\
J-2 & 78.12 & 71.56 & 71.95 \\
J-mean & 80.04 & 72.615 & 70.475 \\
WJ-1 & 95.45 & 93.66 & 88.98 \\
WJ-2 & 89.47 & 84.89 & 87.92 \\
WJ-mean & 92.46 & 89.275 & 88.45 \\
\hline
\end{tabular}

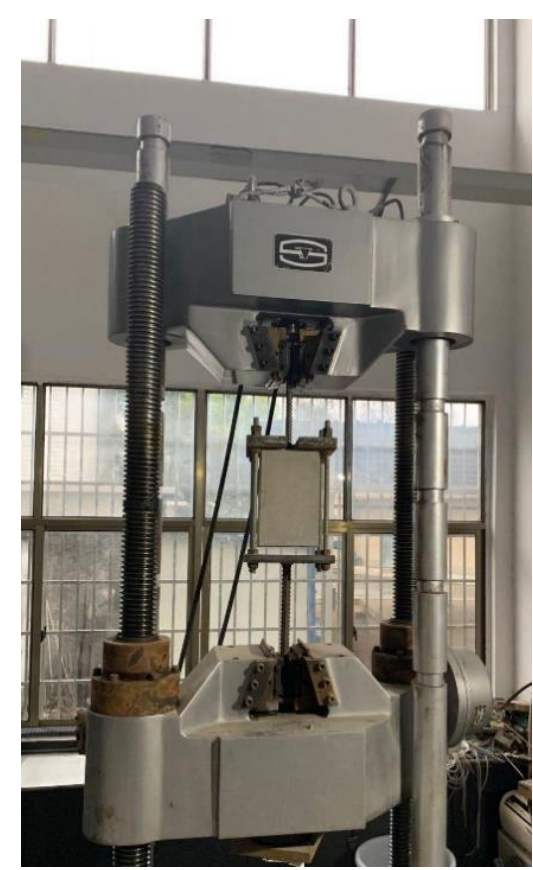

Figure 20. Device and procedure of bonding tests

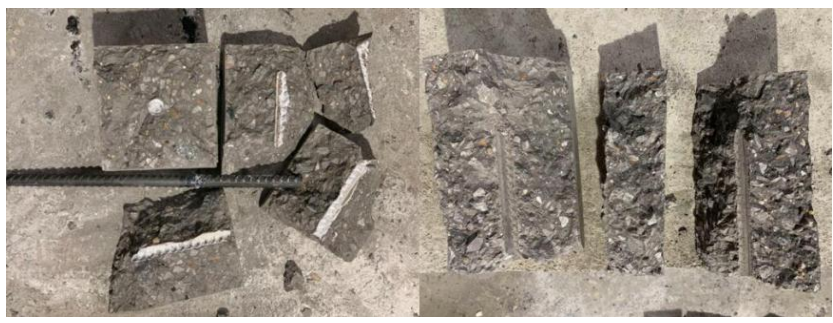

Figure 21. Failure morphology of samples at $0.2 \mathrm{kN} / \mathrm{s}$

As shown in Table 4, under the constant loading speed of $0.2 \mathrm{kN} / \mathrm{s}$, the mean maximum destructive force of $\mathrm{WJ}$ was $86.57 \%$ of that of J. That ratio reached $81.34 \%$ at $0.5 \mathrm{kN} / \mathrm{s}$, and $79.68 \%$ at $0.8 \mathrm{kN} / \mathrm{s}$. The mean maximum destructive force of both WJ and J decreased with the increase of constant loading speed. Under the three constant loading speeds, splitting failure occurred in concrete, and rebars were pulled out in all samples. However, at the constant loading speed of $0.2 \mathrm{kN} / \mathrm{s}$, the reinforced concrete samples were broken with wide cracks (Figure 21), suggesting that the concrete breaking is the main failure cause. At the speed of 0.5 or $0.8 \mathrm{kN} / \mathrm{s}$, the samples were intact with narrow cracks (Figure 22), and the main damage was the pull-out of rebars. The test results prove that the best bonding effect of the adhesive on rebar and concrete appears at a low constant loading speed. 


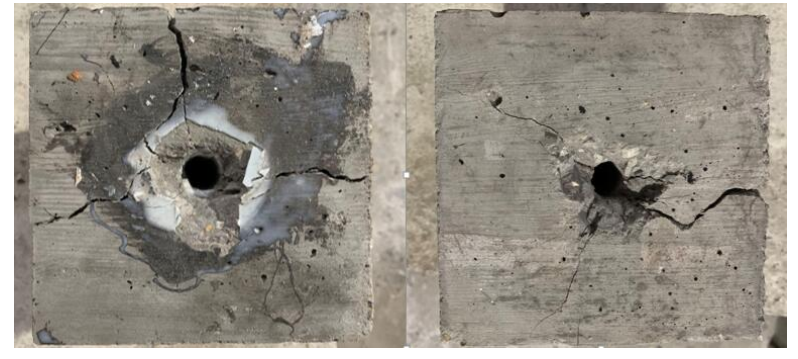

Figure 22. Failure morphology of samples at $0.5 \mathrm{kN} / \mathrm{s}$ and $0.8 \mathrm{kN} / \mathrm{s}$

\section{CONCLUSIONS}

This paper mainly investigates the effect of hydrothermal aging on the dynamic mechanical properties of a new room temperature-cured building structural adhesive, as well as the application of the adhesive in concrete structure. The hydrothermal aging conditions were simulated with a hydrothermal aging oven. The simulated conditions are closer to the actual service environment of the adhesive than those achieved by water immersion method. The test results show that the properties of the structural adhesive changed little after aging at four different humidity levels for 30 days, a sign of good resistance to hydrothermal aging. Moreover, the adhesive was applied to repair and strength cracked concrete blocks. The application results show that the compressive strength of $\mathrm{C} 2$ was $61.6 \%$ of that of $\mathrm{C} 1$, and that compressive strength of $\mathrm{C} 3$ was $90.5 \%$ of that of $\mathrm{C} 1$. The comparison demonstrates that the adhesive can significantly improve the compressive strength of concrete blocks. Furthermore, bonding tests demonstrate that the mean maximum destructive force of both WJ and $\mathrm{J}$ decreased with the increase of constant loading speed, and the best bonding effect was achieved at a low constant loading speed $(0.2 \mathrm{kN} / \mathrm{s})$. The research successfully explores how to characterize the hydrothermal aging behavior of the structural adhesive, and how to apply it to concrete structures. However, this paper only considers the effect of moisture on the performance of the adhesive, and the tests were only targeted at simple concrete components. The future research will take account of many other factors worthy of further discussion, such as light and temperature, and consider more complicated building structures and building materials in the actual engineering projects.

\section{ACKNOWLEDGEMENTS}

This work was supported by the Natural Science Foundation of Henan Province of China (Grant No.: 212300410234) and the Nanhu Scholars Program for Young Scholars of XYNU.

\section{REFERENCES}

[1] Moussa, O., Vassilopoulos, A.P., Castro, J.D., Keller, T. (2013). Long-term development of thermophysical and mechanical properties of cold-curing structural adhesives due to post-curing. Journal of Applied Polymer Science, 127(4): 2490-2496. https://doi.org/10.1002/app.37965

[2] Campana, C., Leger, R., Sonnier, R., Ferry, L., Ienny, P. (2018). Effect of post curing temperature on mechanical properties of a flax fiber reinforced epoxy composite.
Composites Part A: Applied Science and Manufacturing, 107: 171-179.

https://doi.org/10.1016/j.compositesa.2017.12.029

[3] Maljaee, H., Ghiassi, B., Lourenco, P.B. (2017). Effect of synergistic environmental conditions on thermal properties of a cold curing epoxy resin. Composites Part B Engineering, 113: 152-163. https://doi.org/10.1016/j.compositesb.2017.01.027

[4] Pethrick, R.A. (2014). Design and ageing of adhesives for structural adhesive bonding-a review. Proceedings of the Institution of Mechanical Engineers Part L Journal of Materials Design \& Applications, 229: 349-379. https://doi.org/10.1177/1464420714522981

[5] Lettieri, M., Frigione, M. (2012). Effects of humid environment on thermal and mechanical properties of a cold-curing structural epoxy adhesive. Construction \& Building Materials, 30: 753-760. https://doi.org/10.1016/j.conbuildmat.2011.12.077

[6] Yu, B., Keller, T. (2011). Effects of thermal loading history on structural adhesive modulus across glass transition. Construction \& Building Materials, 25(4): 2162-2168.

https://doi.org/10.1016/j.conbuildmat.2010.11.012

[7] Fernández-García, M., Chiang, M.Y.M. (2002). Effect of hygrothermal aging history on sorption process, swelling, and glass transition temperature in a particle-filled epoxy-based adhesive. Journal of Applied Polymer Science, $\quad 84(8)$ : 1581-1591. https://doi.org/10.1002/app.10447

[8] Moosburger-Will, J., Greisel, M., Horn, S. (2015). Physical aging of partially crosslinked rtm6 epoxy resin. Journal of Applied Polymer Science, 131(23): 205-212. https://doi.org/10.1002/app.41121

[9] Yue, Y.J., Chen, F., Liu, Y., Jing, Y.Q. (2013). Research on the influence of epoxy resin from hydrothermal aging. Applied Mechanics and Materials, 331: 403-406. https://doi.org/10.4028/www.scientific.net/AMM.331.4 03

[10] Liu, L.S., Song, L.L., Li, J.L. (2011). Effects of accelerated aging period of time at $180^{\circ} \mathrm{C}$ on tensile strength of 3-dimension-4-direction braided/epoxy resin composites. Advanced Materials Research, 382: 312-315. https://doi.org/10.4028/www.scientific.net/AMR.382.31 2

[11] Song, L., Li, J. (2012). Effects of heat accelerated aging on tensile strength of three dimensional braided/epoxy resin composites. Polymer Composites, 33(9): 16351643. https://doi.org/10.1002/pc.22284

[12] Carlberger, T., Biel, A., Stigh, U. (2009). Influence of temperature and strain rate on cohesive properties of a structural epoxy adhesive. International Journal of Fracture, 155(2): 155-166. https://doi.org/10.1007/s10704-009-9337-4

[13] Zhang, M., Sun, B.Z., Gu, B.H. (2016). Accelerated thermal ageing of epoxy resin and 3-d carbon fiber/epoxy braided composites. Composites Part A: Applied Science \& Manufacturing. 85: 163-171. https://doi.org/10.1016/j.compositesa.2016.03.028

[14] Ferrier, E., Rabinovitch, O., Michel, L. (2016). Mechanical behavior of concrete-resin/adhesive-FRP structural assemblies under low and high temperatures. Construction and Building Materials, 127: 1017-1028. https://doi.org/10.1016/j.conbuildmat.2015.12.127

[15] Banea, M.D., De Sousa, F.S.M., Da Silva, L.F.M., 
Campilho, R.D.S.G., de Pereira, A.B. (2011). Effects of temperature and loading rate on the mechanical properties of a high temperature epoxy adhesive. Journal of Adhesion Science and Technology, 25(18): 24612474. https://doi.org/10.1163/016942411X580144

[16] Zhang, J., Zhang, Y.X., Yang, J. (2015). Investigation on epoxy creep behaviors at ambient and hydrothermal environment. J. Mech. Strength., 37: 237-245. https://doi.org/10.1016/j.polymer.2011.05.056

[17] Liu, S., Cheng, X., Zhang, Q., Zhang, J., Bao, J., Guo, X. (2016). An investigation of hygrothermal effects on adhesive materials and double lap shear joints of CFRP composite laminates. Composites Part B: Engineering, 91: $\quad$ 431-440. https://doi.org/10.1016/j.compositesb.2016.01.051

[18] Silva, P., Fernandes, P., Sena-Cruz, J., Xavier, J., Castro, F., Soares, D. (2016). Effects of different environmental conditions on the mechanical characteristics of a structural epoxy. Composites Part B Engineering, 88: 5563. https://doi.org/10.1016/j.compositesb.2015.10.036

[19] Frigione, M., Aiello, M.A., Naddeo, C. (2006). Water effects on the bond strength of concrete/concrete adhesive joints. Construction and Building Materials, 20(10): 957-970. https://doi.org/10.1016/j.conbuildmat.2005.06.015

[20] Wang, Z., Xian, G., Zhao, X.L. (2018). Effects of hydrothermal aging on carbon fibre/epoxy composites with different interfacial bonding strength. Construction and Building Materials, 161: 634-648. https://doi.org/10.1016/j.conbuildmat.2017.11.171

[21] Tian, F., Luo, Y., Yin, S., Wang, H., Cao, C. (2015). Dynamic viscoelastic properties of polyvinyl chloride with physical aging. Korea-Australia Rheology Journal, 27(4): 259-266. https://doi.org/10.1007/s13367-0150026-8

[22] Alessi, S., Conduruta, D., Pitarresi, G., Dispenza, C., Spa Da Ro, G. (2011). Accelerated ageing due to moisture absorption of thermally cured epoxy resin/polyethersulphone blends. thermal, mechanical and morphological behaviour. Polymer Degradation \& Stability, $\quad 96(4)$ : 642-648. https://doi.org/10.1016/j.polymdegradstab.2010.12.027

[23] Benzarti, K., Chataigner, S., Quiertant, M., Marty, C., Aubagnac, C. (2011). Accelerated ageing behaviour of the adhesive bond between concrete specimens and CFRP overlays. Construction and Building Materials, 25(2):

523-538. https://doi.org/10.1016/j.conbuildmat.2010.08.003

[24] Colombini, D., Martinez-Vega, J.J., Merle, G. (2002). Influence of hydrothermal ageing and thermal treatments on the viscoelastic behavior of dgeba-mcdea epoxy resin. Polymer Bulletin, 48(1): 75-82. https://doi.org/10.1007/s00289-002-0009-z

[25] Fitriah, S.N., Majid, M.A., Ridzuan, M., Daud, R., Gibson, A.G., Assaleh, T.A. (2017). Influence of hydrothermal ageing on the compressive behaviour of glass fibre/epoxy composite pipes. Composite Structures, 159: 350-360. https://doi.org/10.1016/j.compstruct.2016.09.078.

[26] Deroiné, M., Le Duigou, A., Corre, Y.M., Le Gac, P.Y., Davies, P., César, G., Bruzaud, S. (2014). Accelerated ageing and lifetime prediction of poly (3hydroxybutyrate-co-3-hydroxyvalerate) in distilled $\begin{array}{llll}\text { water. } & \text { Polymer } & \text { 70-78. }\end{array}$ https://doi.org/10.1016/j.polymertesting.2014.07.018

[27] Fraga, A.N., Alvarez, V.A., Vazquez, A., Osa, O. (2003). Relationship between dynamic mechanical properties and water absorption of unsaturated polyester and vinyl ester glass fiber composites. Journal of Composite Materials, 37(17): 1553-1574. https://doi.org/10.1177/0021998303029421

[28] Goertzen, W.K., Kessler, M.R. (2007). Dynamic mechanical analysis of carbon/epoxy composites for structural pipeline repair. Composites Part B Engineering, 38(1): https://doi.org/10.1016/j.compositesb.2006.06.002

[29] Herzog, B., Gardner, D.J., Lopez-Anido, R., Goodell, B. (2005). Glass-transition temperature based on dynamic mechanical thermal analysis techniques as an indicator of the adhesive performance of vinyl ester resin. Journal of Applied Polymer Science, 97(6): 2221-2229. https://doi.org/10.1002/app.21868

[30] Frigione, M., Lettieri, M., Mecchi, A.M. (2006). Environmental effects on epoxy adhesives employed for restoration of historical buildings. Journal of Materials in Civil Engineering, 18(5): 715-722. https://doi.org/10.1061/(ASCE)0899. 1561(2006)18:5(715)

[31] Vietri, U., Guadagno, L., Raimondo, M., Vertuccio, L., Lafdi, K. (2014). Nanofilled epoxy adhesive for structural aeronautic materials. Composites Part B Engineering, 61: 73-83. https://doi.org/10.1016/j.compositesb.2014.01.032

[32] Prolongo, S.G., Rosario, G.D., Uren, A. (2006). Comparative study on the adhesive properties of different epoxy resins. International Journal of Adhesion \& Adhesives, 26(3): 125-132. https://doi.org/10.1016/j.ijadhadh.2005.02.004

[33] Kotynia, R., Adamczewska, K., Strkowska, A., Masowski, M., Strzelec, K. (2017). Effect of accelerated curing conditions on shear strength and glass transition temperature of epoxy adhesives. Procedia Engineering, 193: 423-430 https://doi.org/10.1016/j.proeng.2017.06.233

[34] Savvilotidou, M., Vassilopoulos, A.P., Frigione, M., Keller, T. (2017). Effects of aging in dry environment on physical and mechanical properties of a cold-curing structural epoxy adhesive for bridge construction. Construction and Building Materials, 140: 552-561. https://doi.org/10.1016/j.conbuildmat.2017.02.063

[35] Savvilotidou, M., Vassilopoulos, A.P., Frigione, M., Keller, T. (2017). Development of physical and mechanical properties of a cold-curing structural adhesive in a wet bridge environment. Construction and Building Materials, 144: 115-124. https://doi.org/10.1016/j.conbuildmat.2017.03.145

[36] Michels, J., Cruz, J.S., Christen, R., Czaderski, C., Motavalli, M. (2016). Mechanical performance of coldcuring epoxy adhesives after different mixing and curing procedures. Composites Part B Engineering, 98: 434-443. https://doi.org/10.1016/j.compositesb.2016.05.054

[37] Carbas, R.J.C., Marques, E.A.S., Da Silva, L.F.M., Lopes, A.M. (2014). Effect of cure temperature on the glass transition temperature and mechanical properties of epoxy adhesives. The Journal of Adhesion, 90(1): 104119. https://doi.org/10.1080/00218464.2013.779559

[38] Czaderski, C., Martinelli, E., Michels, J., Motavalli, M. (2012). Effect of curing conditions on strength 
development in an epoxy resin for structural strengthening. Composites Part B, 43(2): 398-410. https://doi.org/10.1016/j.compositesb.2011.07.006

[39] Michels, J., Widmann, R., Czaderski, C., Allahvirdizadeh, R., Motavalli, M. (2015). Glass transition evaluation of commercially available epoxy resins used for civil engineering applications. Composites Part B Engineering, 77: 484-493. https://doi.org/ 0.1016/j.compositesb.2015.03.053

[40] Carbas, R.J.C., Marques, E.A.S., Da Silva, L.F.M., Lopes, A.M. (2014). Effect of cure temperature on the glass transition temperature and mechanical properties of epoxy adhesives. The Journal of Adhesion, 90(1): 104119. https://doi.org/10.1080/00218464.2013.779559

[41] Li, H., Luo, Y., Hu, D., Jiang, D. (2019). Effect of hydrothermal aging on the dynamic mechanical performance of the room temperature-cured epoxy adhesive. Rheologica Acta, 58(1): 9-19. https://doi.org/10.1007/s00397-018-1121-9

[42] Li, H., Luo, Y., Hu, D. (2018). Long term creep assessment of room-temperature cured epoxy adhesive by time-stress superposition and fractional rheological model. Applied Rheology, 28(6): 64796. https://doi.org/10.3933/ApplRheol-28-64796

[43] Karbhari, V.M., Qiang, W. (2004). Multi-frequency dynamic mechanical thermal analysis of moisture uptake in e-glass/vinylester composites. Composites Part B Engineering, 35(4): 299-304. https://doi.org/10.1016/j.compositesb.2004.01.003

[44] Butt, R.I., Cotter, J.L. (1976). The effect of high humidity on the dynamic mechanical properties and thermal transitions of an epoxy-polyamide adhesive. The Journal of Adhesion, 8(1): 11-19. https://doi.org/10.1080/00218467608075067

[45] Ivanova, K.I., Pethrick, R.A., Affrossman, S. (2002). Hygrothermal aging of rubber-modified and mineralfilled dicyandiamide-cured DGEBA epoxy resin. III. Dielectric spectroscopy investigation. Journal of Applied Polymer Science, 84(5): 1011-1024. https://doi.org/10.1002/app.10368

[46] Chang, S.H., Kim, H.S. (2011). Investigation of hygroscopic properties in electronic packages using molecular dynamics simulation. Polymer, 52(15): 34373442. https://doi.org/10.1016/j.polymer.2011.05.056 